Article

\title{
Flow Characteristics at a River Diversion Juncture and Implications for Juvenile Salmon Entrainment
}

\author{
Yong G. Lai
}

Citation: Lai, Y.G. Flow

Characteristics at a River Diversion

Juncture and Implications for

Juvenile Salmon Entrainment. Fluids 2022, 7, 98. https://doi.org/10.3390/ fluids7030098

Academic Editor: Mehrdad Massoudi

Received: 10 January 2022

Accepted: 4 March 2022

Published: 7 March 2022

Publisher's Note: MDPI stays neutral with regard to jurisdictional claims in published maps and institutional affiliations.

Copyright: (C) 2022 by the author. Licensee MDPI, Basel, Switzerland. This article is an open access article distributed under the terms and conditions of the Creative Commons Attribution (CC BY) license (https:// creativecommons.org/licenses/by/ $4.0 /)$.
Technical Service Center, U.S. Bureau of Reclamation, Denver, CO 80225, USA; ylai@usbr.gov; Tel.: +1-303-445-2560

\begin{abstract}
Flow structures at a river diversion juncture are complex and have been studied extensively. Their impact on the juvenile salmon entrainment into the side channel, however, is less investigated, and based mostly on empiricism. In this study, a Eulerian fish tracking model is developed and used in conjunction with a 3D flow solver to quantitatively evaluate the implications of complex flow characteristics at typical junctures on fish entrainment. First, the flow model is validated with the available experimental data, key flow structures are examined using the results, and their implications for fish entrainment are discussed. Next, the numerical fish tracking model is used to show that the cross-sectional fish distribution immediately upstream of a juncture is an important factor that controls fish entrainment efficiency. Fish entrainment efficiency curves are developed for different flow diversion ratios and fish distribution patterns and used to shed light on the reasons behind some field-observed fish entrainment patterns. Further, the model is used to show that the secondary flow in a river bend may have a significant impact on fish entrainment at flow junctures, in agreement with field observations. Finally, a submerged vane is demonstrated to be a potential management option to locally generate secondary flows upstream of a juncture to achieve the desired fish entrainment property.
\end{abstract}

Keywords: fish track; fish entrainment; fish passage; juncture flow; CFD

\section{Introduction}

Flow diversion is encountered frequently in rivers, whether manmade or natural. Manmade diversion has been applied for several purposes including water supply (irrigation canals or run-of-the-river intakes) and stream restoration (e.g., side channel construction). Natural diversion includes river bifurcation which separates river flows into two or more streams and occurs often in meandering and braided rivers.

Flow at a diversion juncture is complex and has been the subject of extensive studies [1-4]. The complex juncture flow structures are illustrated in Figure 1, which identifies multiple flow zones as discussed in [1]: a primary separation zone near the entrance of the side channel, a stagnation zone at the downstream corner of the junction, a potential secondary separation zone in the main channel on the opposite side of the juncture, and a contraction flow zone in the side channel. Further, two secondary circulations (helical motions) are usually generated due to the intricate interactions among the longitudinal pressure gradient, shear force, and curvature-induced centrifugal force; a clockwise secondary circulation is formed along the right wall of the side channel, while a counter-clockwise secondary flow is developed along the left wall of the main channel downstream of the juncture. The relative strengths of the secondary flows, recirculation zones, and the associated flow turbulence are dictated by the total flow in the main channel, the percentage of flows diverted into the side channel, and the juncture geometry (e.g., side channel angle, cross-section shape, sill elevation, and channel width and depth). The flow structures may change in time in a natural environment due to the unsteady flow hydrology or tidal influence. 


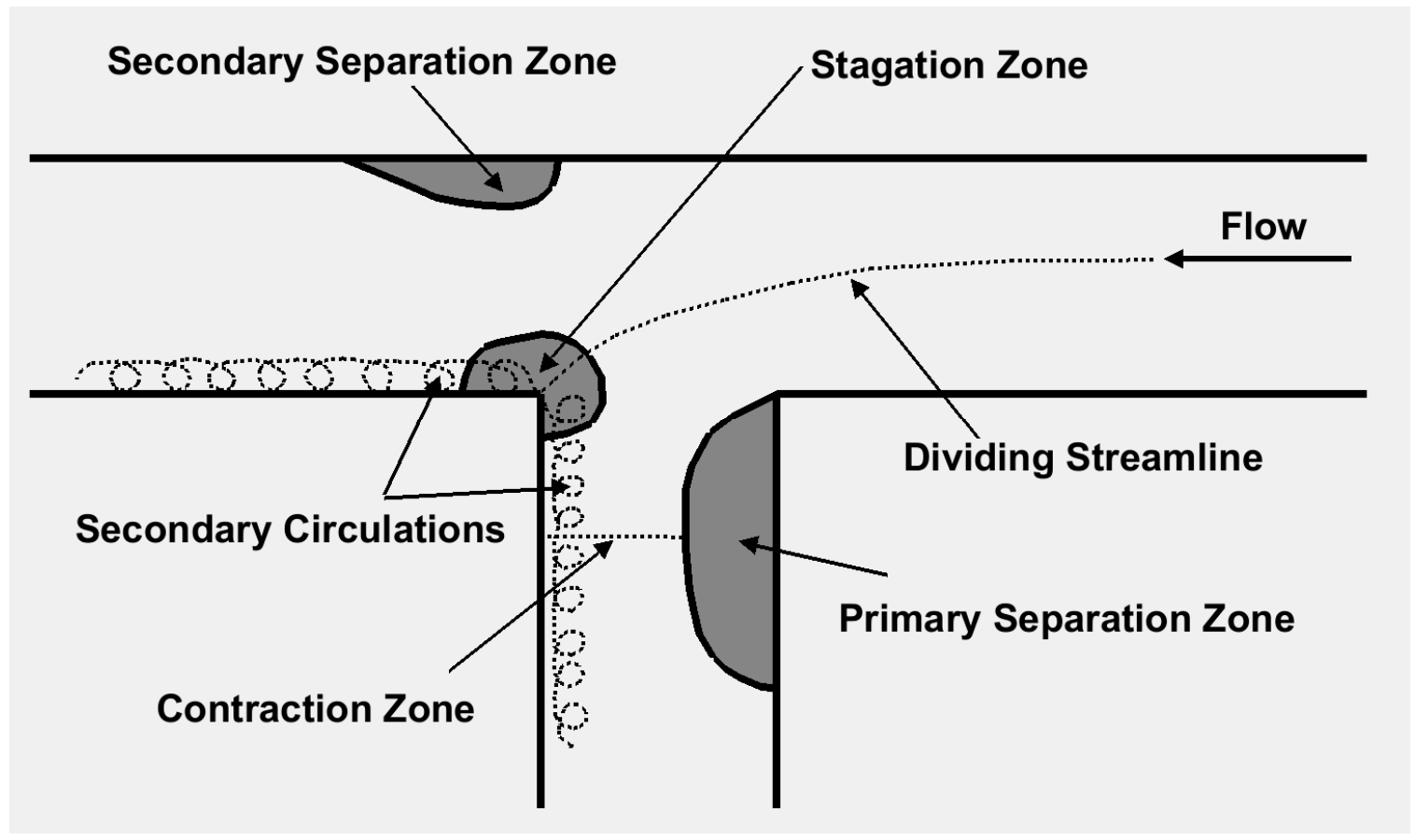

Figure 1. Schematic illustrating major flow structures at a typical flow juncture according to [1].

The complex flow structures at a diversion juncture have led to non-intuitive, yet interesting, phenomena of practical importance. One such phenomenon is the bedload transport process at the juncture-first reported by Bulle [5]. The so-called Bulle Effect refers to the condition where the proportion of incoming bedload that enters the side channel is significantly higher than the proportion of incoming flow that is diverted. For example, with a $50 \%$ water diversion, about $90 \%$ of the bedload would enter the side channel. Since the Bulle study, a large body of literature has been devoted to the sediment entrainment study at flow junctures in an attempt to explain the mechanisms behind this disproportion. See the recent review by Dutta and Garcia [6] for a thorough discussion.

Similarly, the juncture flow features are expected to have notable impacts on fish entrainment into the side channel. However, few studies have been reported on the subject, which motivated the present research. In recent years, fish biologists have become interested in this subject as a way to influence the entrainment of fish towards pathways of higher survival and away from pathways of lower survival. The downstream migration of juvenile anadromous salmonid has been a subject of intense interest over the years. These fish often travel great distances from spawning habitats in freshwater rivers to the ocean, sometimes located hundreds of kilometers away. As juveniles migrate downstream, they may encounter different rearing habitats and migration routes. Some of the routes are advantageous for fish survival and growth, such as those with productive floodplains and side channels [7-9]. Others may lead to increased mortality, such as those with agricultural diversions, turbines, industrial cooling systems, or habitats with high predator population $[10,11]$. A good example is the juvenile Chinook salmon migration from natural tributaries to the ocean in the Sacramento (San Joaquin River Delta, California) a Delta consisting of a complex network of natural and artificial channels and having been highly altered for water conveyance [12]. A migrating juvenile may move along one of the four routes through the Delta, and two of them lead to the interior Delta which exhibits lowest survival rates $[13,14]$. This low survival is caused by higher predation rate, longer migration time, and existence of the water pumping stations [15].

Although patterns of habitat use have been relatively well studied [16], entrainment characteristics into alternative routes are less studied and our current understanding is limited $[17,18]$. Even more difficult is to estimate or predict the proportion of a fish population 
that is entrained into an alternative route at a river diversion juncture and under a given management strategy $[17,18]$. Yet, there is an increasing interest in better understanding the factors controlling the migration route selection at key flow junctures so that management strategies may be developed and adopted to improve juvenile survival, which will contribute to recovering imperiled salmon populations reliant on migrating through the Delta. For example, a recent project at the Fremont Weir section of the Sacramento River has focused on the relocation and improvement of the approaching channel and notch structure in an attempt to increase the entrainment of the juvenile salmon into the Yolo Bypass where juveniles are expected to have a higher survival rate [19].

In the present study, a numerical modeling tool is developed to estimate the fish entrainment rate at a flow diversion juncture and shed light on the entrainment characteristics. The method builds on the hypothesis that local flow hydrodynamics is a dominant factor affecting fish entrainment, among other variables. In the following discussion, fish attraction refers to a junction where fish entrainment into the side channel is encouraged, while fish rejection refers to the situation where entrainment is undesired.

The use of numerical models for fish passage study is an emerging field. Early work was mostly on juvenile salmonid migration through hydropower dams. Such studies were reported, e.g., by [20-22]. These studies have achieved some success and demonstrated the benefits and effectiveness of adopting the numerical modeling approach. The success at reservoirs, however, has not been transferable to the downstream migrating fish entrainment at river junctures or upstream migrating fish passage. A primary issue is the lack of understanding of fish responses to local flow features in the riverine environment. Recent studies have, therefore, focused on increasing our understanding of fish behaviors in response to local flow hydrodynamics and other environment parameters. Relevant studies include McNamara et al. [23], Goodwin et al. [24], Dabiri [25], Oteiza et al. [26], Bever and MacWilliams [27], Ramon et al. [28], Goodwin et al. [29], among others.

Studies for fish entrainment at river junctures have mostly been performed in the field through tracking. The measured data are often used to develop empirical relations that correlate fish entrainment to flow variables, e.g., the flow diversion ratio [13,14,30-32]. There is a lack of numerical modeling studies to my knowledge. A recent study was conducted by Ramon et al. [28] who applied a numerical model at the Georgiana Slough juncture of the Sacramento River. The study examined the impact of fish distribution and bend-generated secondary flows on fish entrainment using a passively driven particle model. The present study builds on the Ramon study, but differs in several aspects: (1) the flow model is based on the three-dimensional (3D) Reynolds-Averaged NavierStokes (RANS) solver without the hydrostatic assumption (Ramon study adopted the hydrostatic-assumption flow model); (2) the effect of non-uniform fish distribution on fish entrainment is investigated explicitly, focusing on both vertical and lateral fish distributions, and compared with the measured data; and (3) secondary flows that are generated by both bend and submerged vane and their fish attraction effects are explored. Hance et al. [33] recently proposed a conceptual model for predicting fish entrainment using the concepts of streakline, entrainment zone and fish distribution. Our study follows a similar concept, but the streakline and entrainment zone are predicted by the 3D RANS model, not the field-measured data.

\section{Material and Methods}

\subsection{Fluid FLow Numerical Method}

This study adopts a similar approach to Ramon et al. [28] in that the flow field is obtained from a numerical model while fish tracking is based on the passive-particle assumption. The 3D flow model adopted, however, is a more accurate, non-hydrostatic, RANS-based solver. Specifically, the 3D RANS model of Lai [34] is adopted, which was 
improved significantly by Lai et al. [35] for flows with complex geometry. The RANS equations may be expressed in tensor form for incompressible flows as:

$$
\begin{gathered}
\frac{\partial U_{j}}{\partial x_{j}}=0 \\
\frac{\partial U_{i}}{\partial t}+\frac{\partial\left(U_{j} U_{i}\right)}{\partial x_{j}}=\frac{\partial}{\partial x_{j}}\left(v \frac{\partial U_{i}}{\partial x_{j}}+\tau_{i j}\right)-\frac{\partial P}{\rho \partial x_{i}}+g_{i}
\end{gathered}
$$

In the above, $t$ is time; $x_{j}$ is $j$-th Cartesian coordinate; $U_{j}$ is mean velocity component along coordinate $x_{j} ; \tau_{i j}=-\overline{u_{i} u_{j}}$ is turbulence stress $\left(u_{j}\right.$ is $j$-th turbulent fluctuating velocity component); $P$ is mean pressure; $\rho$ is water density; $v$ is water kinematic viscosity; and $g_{i}$ is $i$-th component of the acceleration due to gravity. Repeated subscript (e.g., $j$ ) means summation over the three Cartesian coordinates.

The turbulent stress $\tau_{i j}$ is related to the mean velocity strain rate using the Boussinesq approximation [36] as:

$$
\tau_{i j}=v_{t}\left(\frac{\partial U_{i}}{\partial x_{j}}+\frac{\partial U_{j}}{\partial x_{i}}\right)-\frac{2}{3} k \delta_{i j}
$$

where $v_{t}$ is the turbulence eddy viscosity computed from a turbulence model and $\delta_{i j}$ is the Kronecker delta (the unit tensor). In this study, the two-equation $k-\varepsilon$ model of Launder and Spalding [37] is adopted. That is, the eddy viscosity is computed by:

$$
v_{t}=C_{\mu} \frac{k^{2}}{\varepsilon}
$$

and the turbulence kinetic energy $(k)$ and the turbulence dissipation rate $(\varepsilon)$ are governed by:

$$
\begin{gathered}
\frac{\partial k}{\partial t}+\frac{\partial\left(U_{j} k\right)}{\partial x_{j}}=\frac{\partial}{\partial x_{j}}\left(\left(v+\frac{v_{t}}{\sigma_{k}}\right) \frac{\partial k}{\partial x_{j}}\right)+G-\varepsilon \\
\frac{\partial \varepsilon}{\partial t}+\frac{\partial\left(U_{j} \varepsilon\right)}{\partial x_{j}}=\frac{\partial}{\partial x_{j}}\left(\left(v+\frac{v_{t}}{\sigma_{\varepsilon}}\right) \frac{\partial \varepsilon}{\partial x_{j}}\right)+C_{\varepsilon 1} \frac{\varepsilon}{k} G-C_{\varepsilon} \frac{\varepsilon^{2}}{k}
\end{gathered}
$$

In the above, $G=\tau_{i j} \frac{\partial U_{i}}{\partial x_{j}}$ is the production rate of the turbulence kinetic energy. The standard turbulence model constants take the following values: $C_{\mu}=0.09, C_{\varepsilon 1}=1.44$, $C_{\varepsilon 2}=1.92, \sigma_{k}=1.0, \sigma_{\varepsilon}=1.3$.

Numerical solution of the above governing equations is not trivial and has been subject to many years of research and development. Key features of the adopted methods include: (1) finite-volume discretization; (2) unstructured polyhedron mesh with cell-centered and co-located mesh arrangement; (3) pressure as the primitive variable; (4) implicit time marching scheme; and (5) pressure-correction method for the continuity equation. Refer to $[34,35]$ for more information.

\subsection{Fish Tracking Method}

Several fish track models are available, from the simple passive particle such as [28] to complex perception-and-response models such as [22,24,38]. In this study, a new Eulerian passive-scalar model is developed. The Eulerian model is simple to operate, accurate in solutions, and sufficient for addressing the fish entrainment questions of interest in this study. The proposed Eulerian model uses a continuous function in space and time- - the fish distribution function (FDF) - to represent the number of fish per unit water volume. FDF may be interpreted as the probability of a fish found at a spatial point in the stream. The Eulerian method is equivalent to the Lagrangian passive-particle model of Ramon et al. [28]. 
The Eulerian equation governing the FDF may be written as:

$$
\frac{\partial F_{d}}{\partial t}+\frac{\partial\left(U_{j} F_{d}\right)}{\partial x_{j}}=0
$$

where $F_{d}$ is the fish distribution function (number of fish per unit volume). The equation reflects the fact that FDF is advected by the flowing water. The dispersion/diffusion term may be added to include the fish drift behaviors but is not done in the present study as there is no known theoretical basis for it. Source terms may also be included to incorporate fish responses to observed fish behaviors, e.g., the tendency of fish to stay away from high shear stress areas (e.g., banks). These are not explored in this study. The numerical solution of Equation (7) follows the same approach as the RANS equation solver of [34]. Given an initial fish distribution at an upstream location, the unsteady transport of $F_{d}$ through the stream may be numerically simulated, providing information on how fish may be entrained into the side channel of a river juncture.

\subsection{Discussion of Passive Fish Assumption}

A key assumption of the present study is that FDF is passively transported by the flowing water, i.e., fish are treated as passive, responding primarily to flow velocity. This assumption is deemed valid only if the stream velocity is above the fish swim capacity or the cruising speed, as discussed by Blake and Horn [39] and Perry et al. [13], and has been adopted by previous studies (e.g., [28]). In general, there are several fish speeds that may be used to describe the fish swim behaviors such as the sustained speed (about one body length of the fish), the prolonged speed (3.5-5.5 body lengths), and the burst speed (8 to 10 body length) (see [40] who discussed mostly for upstream migration fish). For the downstream migrating juvenile Chinook salmon, the fish cruising speed (or capacity) has been widely used, which is about two body lengths per second [41]. For an average juvenile salmonid length of $100 \mathrm{~mm}$ [16], the fish cruising speed is about $0.2 \mathrm{~m} / \mathrm{s}$. Many fish entrainment studies were reported on the Sacramento River, whose average velocity was found to be mostly higher than this threshold and was used to justify the passive assumption by, e.g., Ramon et al. [28].

In general, fish respond to multiple hydrodynamic stimuli, in addition to the velocity, such as strain rate, turbulence, acceleration, and pressure [21,24]. In a recent study by Gross et al. [38], the behavioral stochastic fish-tracking model was developed to simulate fish migration paths at the juncture of the San Joaquin River and Old River, California. Both hydrodynamic stimuli and fish swimming behaviors were taken into account. The fish swimming speed was computed directly from the acoustic telemetry data and used by the model. Four fish behavior-response modes were incorporated and named passive, surface orientation, rheotaxis, and correlated random walk. Up to eight swimming scenarios were simulated using the above four modes and their combinations. It was found that the route selection of a specific fish was impacted by the active fish swim behavior mode adopted. The predicted fish entrainment rate into the side channel (the Old River for the example study), however, was similar among the passive and active swimming behaviors. The study showed that the passive assumption would be valid at the San Joaquin, Old River juncture if the cumulative variable — such as the percentage of fish entrainment-was the primary interest.

The limitation of the passive assumption should also be emphasized. For streams slower than the swim capacity or when fish perception-and-response is strong, the absolute entrainment rate computed by the model may not be accurate. An example of the increased importance of the fish perception-and-response is when the flow field is subject to much increased flow changes induced by the insertion of an instream structure. Even under such circumstances, the relative comparative results may still be useful [28]. The passive-particle track model may be taken as a first-order representation of the juvenile salmonid movement and used as a quick tool to evaluate the entrainment efficiency at river junctures. 


\section{Result-Discussion}

\subsection{Flow Simulation and Model Validation}

Flow dynamics at junctures have been studied extensively. Early studies were primarily of an experimental and analytical nature. For example, Taylor [42] conducted a detailed experiment of juncture flows in rectangular open channels; the experimental data were used to obtain an empirical (or graphical) solution. Grace and Priest [43] reported experimental results of diversion flows with several channel width ratios and side channel angles. Two flow regimes were identified dependent on the flow Froude number: with and without the standing waves near the side channel entrance. Analytical methods with simplifying assumptions were also developed by, e.g., [44-46].

More extensive laboratory investigations have been carried out since. For example, Neary and Odgaard [1] focused on the 3D flow structures at a juncture and obtained detailed velocity vectors and particle-trace plots in the separation zone. Barkdoll et al. [2] reported an experimental study of a juncture flow, with the open-channel data compared to a pressurized T-junction duct flow. It was found the velocity differences were significant, pointing to the uniqueness of the open channel juncture. They attributed the differences to the secondary flows generated in the open-channel flow that was not present in the pressurized duct flow. Ramamurthy et al. [3] reported an experimental study focusing on the measurement of detailed 3D mean velocity components and water surface profiles in a $90^{\circ}$, sharp-edged, rectangular open-channel juncture. The detailed data were used for a numerical model validation study. Gohari [47] reported an experimental study to examine the flow separation line at the side channel entrance, and the flow results were related to the sediment movement. In particular, the effect of spur dike structures and vanes was examined for their alteration of the flow separation line which impacted the sediment entrainment into the side channel. The study demonstrated that vanes could alter the local flow structures due to the creation of the counter-balancing secondary flow.

Numerical models have also been developed or applied to study the flow characteristics at river junctures. Early numerical modeling was limited to two-dimensional (e.g., [48-50], or laminar flows (e.g., [51]). 3D turbulent flow simulations have been carried out since. Early numerical studies include [3,52-54], among many others. Recently, Babagoli Sefidkoohi et al. [4] reported detailed numerical modeling results at a 90-degree juncture using the commercial CFD model FLOW-3D. Flow patterns, in particular the separation zones, at the juncture were examined by varying the flow depth, flow diversion ratio, and turbulence model.

In this study, the 90-degree juncture of Ramamurthy et al. [3] is simulated to validate the adopted 3D RANS model, before proceeding to investigate fish entrainment at the juncture. The juncture domain is sketched in Figure 2a. The main and side channels have the same rectangular cross-section with the width $(\mathrm{W})$ of $0.61 \mathrm{~m}$ and height $(\mathrm{H})$ of $0.305 \mathrm{~m}$. The upstream section of the main channel has a length of $6.1 \mathrm{~m}(10 \mathrm{~W})$, and the downstream section of the main channel and the side channel have a length of $2.44 \mathrm{~m}(4 \mathrm{~W})$ each. The baseline flow model has a final 3D mesh consisting of 576,000 cells (30 cells in the vertical direction), and is shown in Figure $2 \mathrm{~b}$. The adopted mesh resolution is similar to, but finer than, that adopted by Ramamurthy et al. [3]. To ensure the results are mesh convergent, another model run is carried out with a refined mesh having 1,728,000 cells. Comparison shows that the difference of the predicted velocity between the two meshes are less than one two percentages. A second sensitivity run was performed to investigate the influence of the model domain size on the results by extending the horizontal model domain from $(10 \mathrm{~W}, 4 \mathrm{~W}, 4 \mathrm{~W})$ to $(15 \mathrm{~W}, 8 \mathrm{~W}, 8 \mathrm{~W})$ in terms of the length of the upstream main channel, downstream main channel, and side channel. Again, it was found that the predicted velocity is insensitive to the domain size. 


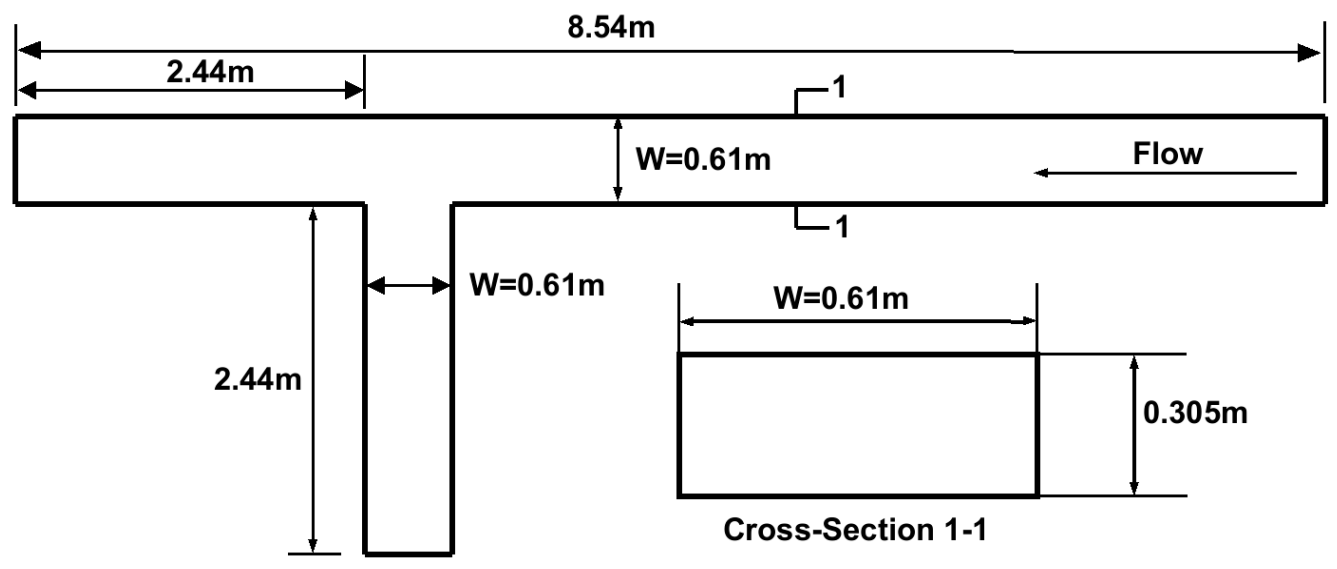

(a) Model domain and geometry

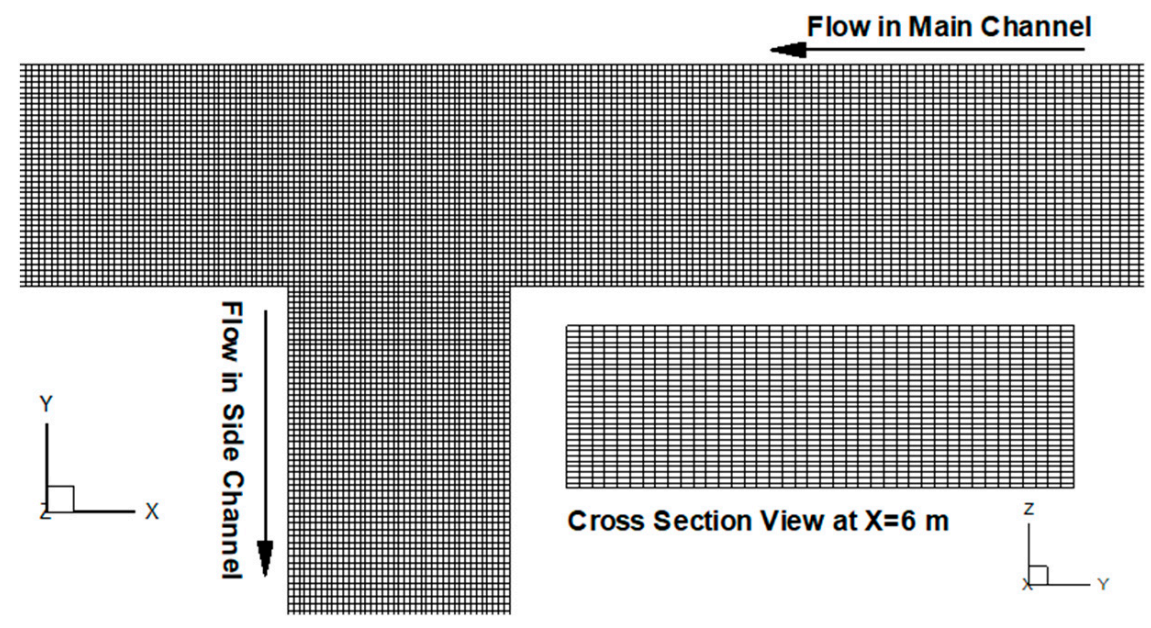

(b) Zoom-in View of the Mesh

Figure 2. Model domain and dimensions of the juncture (a) and the mesh of the baseline model (b).

The flow conditions follow an experimental run of Ramamurthy et al. [3] in which the total discharge in the main channel is $0.046 \mathrm{~m}^{3} / \mathrm{s}$ and the side channel flow is $0.038 \mathrm{~m}^{3} / \mathrm{s}$, leading to $83.8 \%$ the flow diversion rate. The two flow discharges are imposed as the inlet and outlet boundary conditions. At the outlet of the main channel, the measured water elevation is specified. Since the mass conservation is satisfied by the model, the computed flow rate at the main channel outlet is verified to be $0.008 \mathrm{~m}^{3} / \mathrm{s}$. The free surface is determined from the depth-averaged mass and momentum equations. It is found that the use of a flat free surface produces very similar solutions, so the use of free surface algorithm is not important.

The simulated results are compared with the laboratory data of Ramamurthy et al. [3] for model validation. The water surface elevation is compared in Figure 3 along three $y$-lines in the side channel (the water elevation changes the most in the side channel). A detailed comparison of the velocity profiles is shown in Figures 4 and 5. Figure 4 compares the vertical distributions of the v-velocity component at a number of horizontal (xy) points in the side channel, while Figure 5 compares the vertical distributions of u-velocity in the main channel at measured horizontal points. Overall, comparisons of both the free surface elevation and velocity components at the juncture are satisfactory, although some discrepancy is noticeable at a few locations. These results are very similar to those achieved with other CFD models (e.g., [3]). 

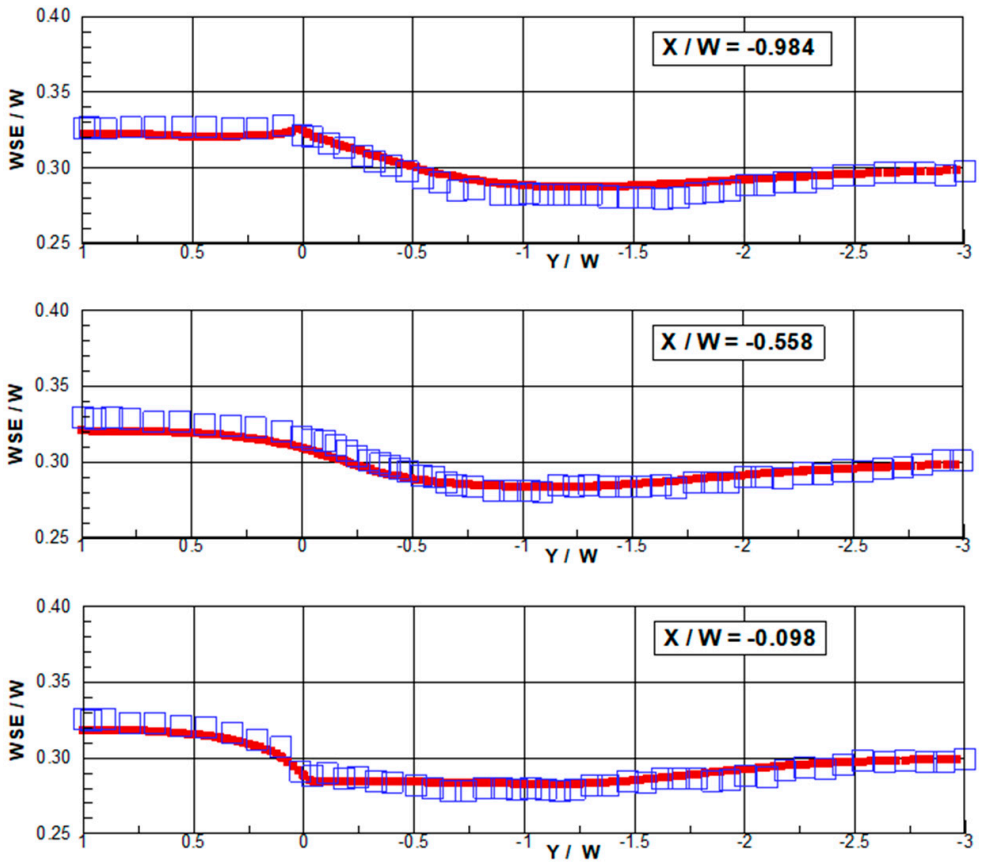

Figure 3. Comparison of the water surface elevation (WSE) variation along the side channel (three $y$ lines); $x=0$ is at the upstream corner of the juncture; the coordinates and water elevation are normalized by the channel width $W$ ).
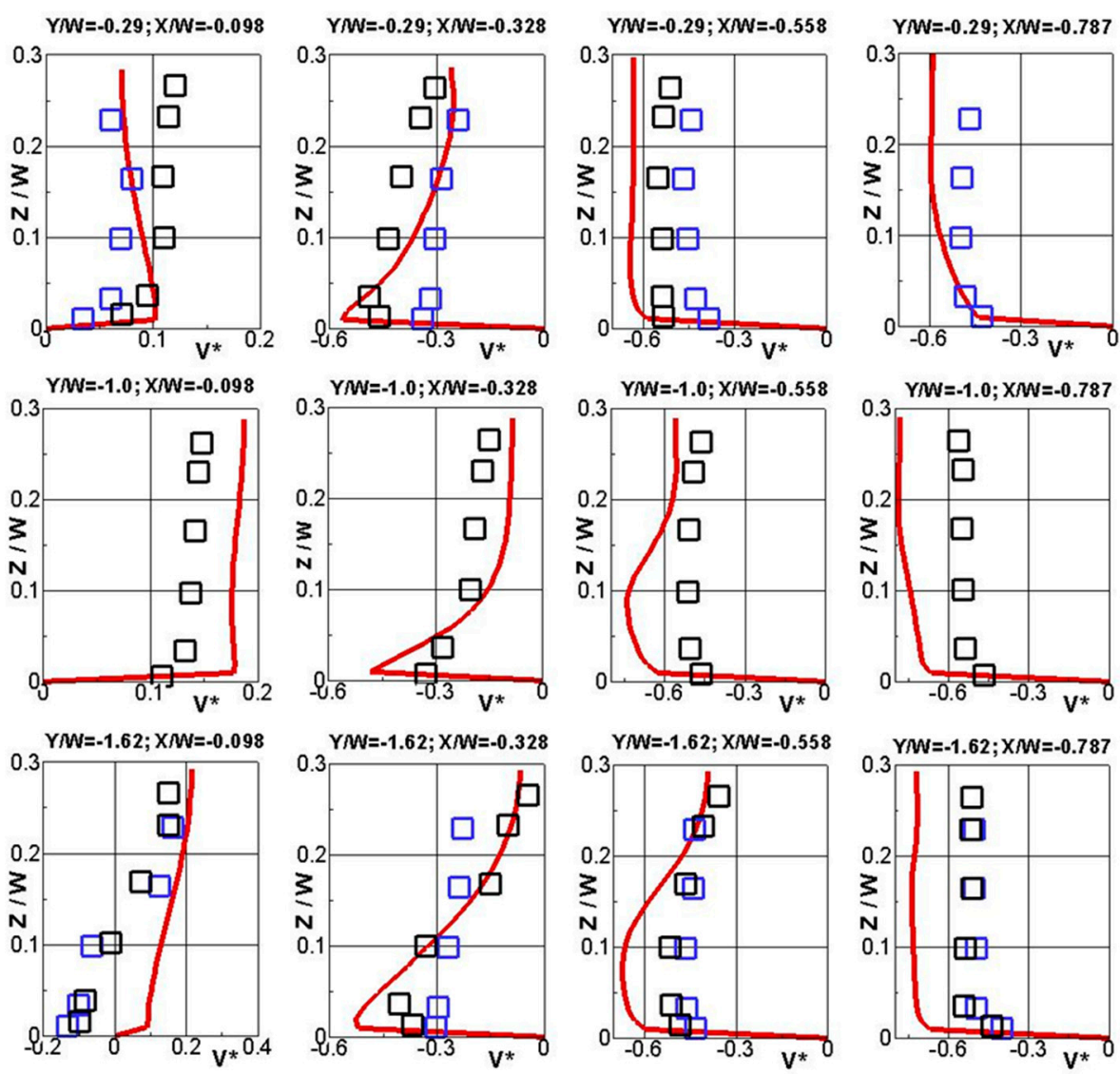

Figure 4. Comparison of v-velocity vertical profiles in the side channel at measured horizontal (xy) points; black symbols are the measured data from Ramamurthy et al. [3] while blue symbols are according to $\mathrm{Qu}[55]$. 

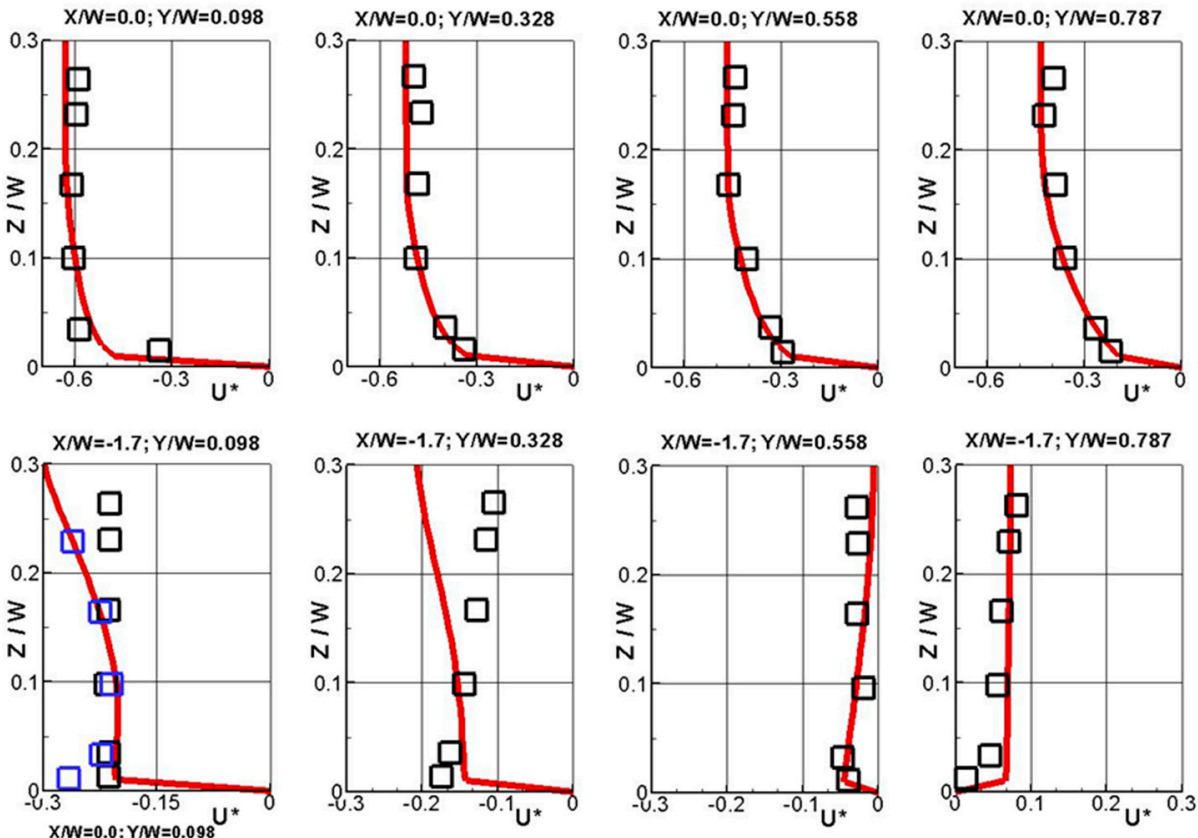

Figure 5. Comparisons of u-velocity vertical profiles in the main channel at measured horizontal (xy) points. black symbols are the measured data from Ramamurthy et al. [3], while blue symbols are according to $\mathrm{Qu}[55]$.

\subsection{Discussion of the Flow Characteristics}

Flow characteristics at the juncture are examined next. Figures 6 and 7 show the velocity features on two horizontal planes: one near the bed $(\mathrm{z} / \mathrm{W}=0.04)$ and the other near the free surface $(z / W=0.27)$. Most flow structures discussed in the Introduction are predicted. The dividing stream-surface in the main channel—or the streakline separating the mainchannel cross-section into the attraction (entrainment) and rejection (non-entrainment) zones-is seen to vary over the water depth. The line moves toward the non-entrainment bank of the main channel with increasing depth. This is consistent with the finding of [1] and suggests that more particles would be entrained into the side channel if they are located close to the bed (the Bulle Effect). Two separation zones are predicted: a strong one in the side channel and a weaker one in the main channel downstream of the juncture. In the side channel, the recirculation zone is larger near the free surface than that near the bed. It is also noted that the streamlines near the bed in the stagnation zone emanate into both side and main channels. This points to the existence of a strong downward fluid flow in the stagnation zone, from free surface towards the bed, which is the outcome of the two counter-rotating secondary flows discussed previously.

It is apparent that the near-bed flow moves predominantly into the side channel, implying that the majority of the bedload sediment, if not all, would move into the side channel. This is consistent with the experimental observation of Bulle [5] who observed that about $90 \%$ of the bedload moved into the side channel, although only $50 \%$ of the flow was diverted. Similar effects are implied for the juvenile fish.

\subsection{Fish Entrainment Result at the Juncture of the Straight Main Channel}

An important research question is how the complex flow structures at river junctures may impact fish entrainment. In the following, the 3D flow model and the Eulerian fish tracking are used to shed light on fish entrainment characteristics at river junctures. It will be shown that, (1) fish distribution upstream of the juncture has a significant impact on the fish entrainment rate, and (2) presence of a secondary flow upstream of the junction may alter the fish entrainment. 

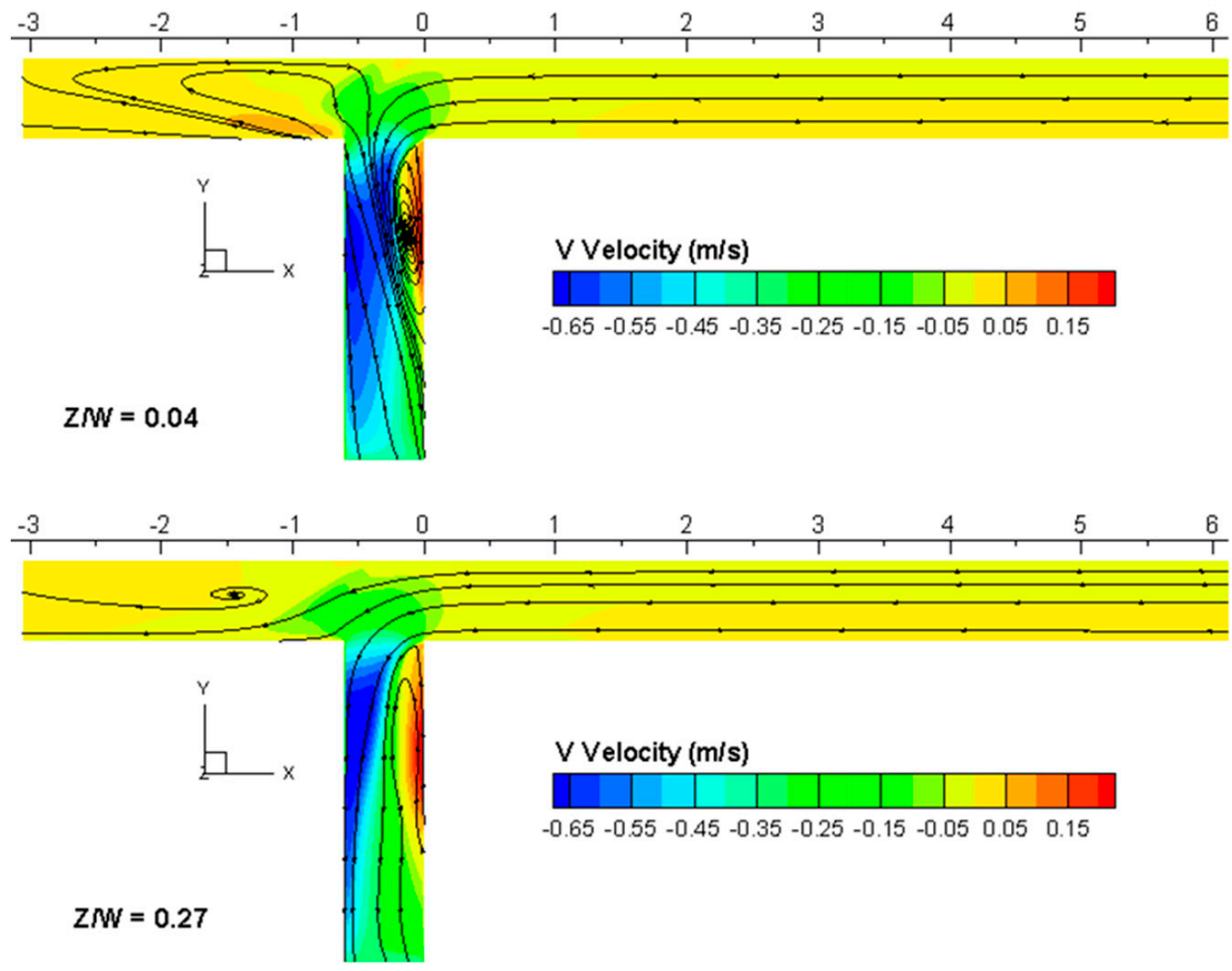

Figure 6. Simulated v-velocity contours and flow streamlines at two horizontal planes; the top figure is near the bed and the bottom one is near the free surface.

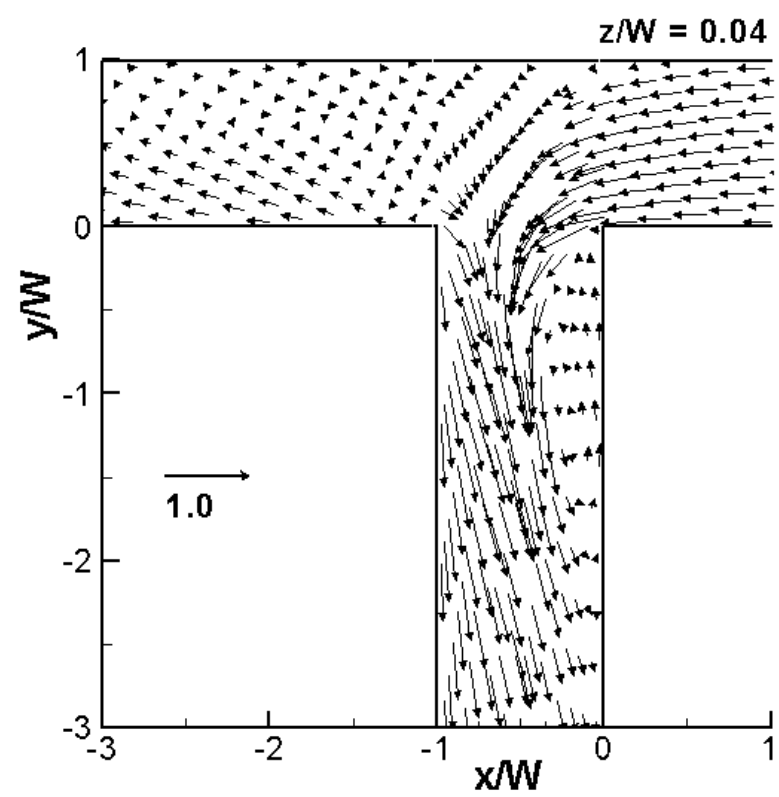

(a) $\mathrm{z} / \mathrm{W}=0.04$

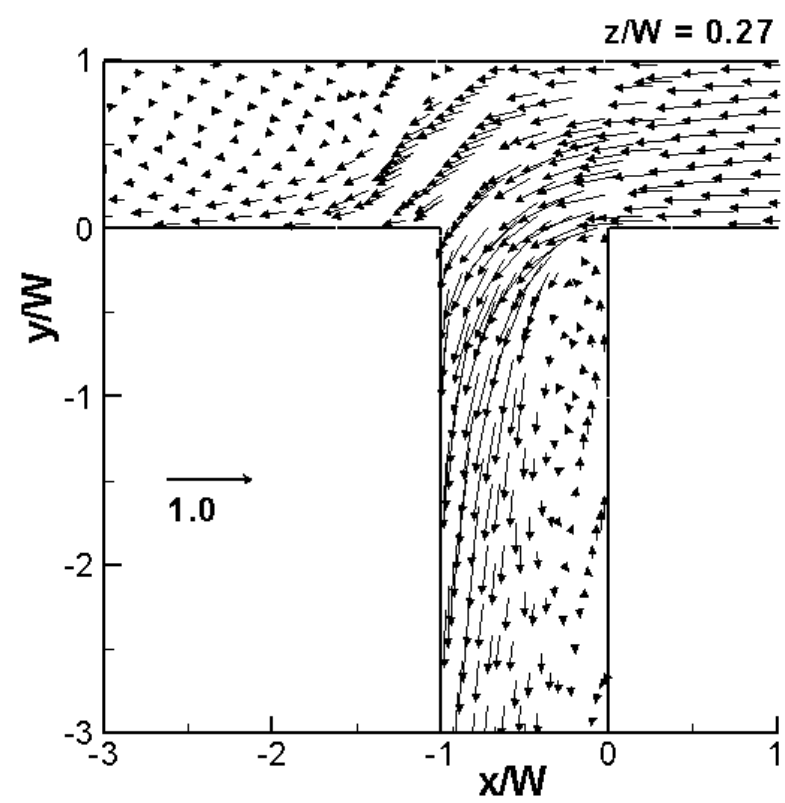

(b) $\mathrm{z} / \mathrm{W}=0.27$

Figure 7. Velocity vector plots at two horizontal planes; figure (a) is near the bed and figure (b) is near the free surface.

Fish entrainment is first examined at the 90-degree diversion juncture of Ramamurthy et al. [3], which has a straight main channel. In addition to the baseline with $83.8 \%$ water diversion rate, two other rates are simulated: $50 \%$ and $20 \%$. These three rates are used to shed light on the fish entrainment characteristics. In particular, the impact 
of upstream fish distribution is examined and discussed. Note that all flow inputs are kept the same, barring the diversion rate.

Four upstream fish distributions are explicitly simulated for each diversion rate using the Eulerian fish tracking model; they were named top, bottom, entrainment side, and non-entrainment side, respectively. Each occupies only half of the channel cross-section upstream of the juncture and represent the school of fish released. They are designed to explore the effect of vertical distribution (surface- versus bottom-oriented) and lateral distribution (entrainment versus non-entrainment side). The twelve model run labels and the corresponding fish entrainment results are tabulated in Table 1 and plotted in Figure 8. The fish entrainment efficiency is defined as the ratio of the percentage of fish entrained to the percentage of flow diverted. The entrainment efficiency of 1.0 means that the fish entrainment rate is equal to the diverted flow rate. A value above 1.0 indicates fish attraction, while a below -1.0 value indicates fish rejection (or barrier).

Table 1. Fish entrainment efficiency for the case of Ramamurthy et al. [3].

\begin{tabular}{lllll}
\hline $\begin{array}{l}\text { Scenario } \\
\text { Label }\end{array}$ & $\begin{array}{l}\text { \% of Flow } \\
\text { Diverted }\end{array}$ & $\begin{array}{l}\text { Fish } \\
\text { Distribution }\end{array}$ & $\begin{array}{l}\text { \% of Fish } \\
\text { Entrained }\end{array}$ & $\begin{array}{l}\text { Fish } \\
\text { Entrainment } \\
\text { Efficiency }\end{array}$ \\
\hline $84 \mathrm{~T}$ & 83.8 & Top Half & 79.4 & 0.95 \\
$84 \mathrm{~B}$ & 83.8 & Bottom Half & 90.3 & 1.08 \\
$84 \mathrm{~L}$ & 83.8 & Entrainment Side Half & 100.0 & 1.20 \\
$84 \mathrm{R}$ & 83.8 & Non-Entrainment Half & 68.3 & 0.81 \\
50T & 50.0 & Top Half & 44.4 & 0.89 \\
50B & 50.0 & Bottom Half & 57.1 & 1.14 \\
50L & 50.0 & Entrainment Side Half & 92.0 & 1.82 \\
50R & 50.0 & Non-Entrainment Half & 9.9 & 0.20 \\
20T & 20.0 & Top Half & 17.9 & 0.90 \\
20B & 20.0 & Bottom Half & 23.0 & 1.15 \\
20L & 20.0 & Entrainment Side Half & 40.0 & 2.0 \\
20R & 20.0 & Non-Entrainment Half & 0.006 & 0.0 \\
\hline
\end{tabular}

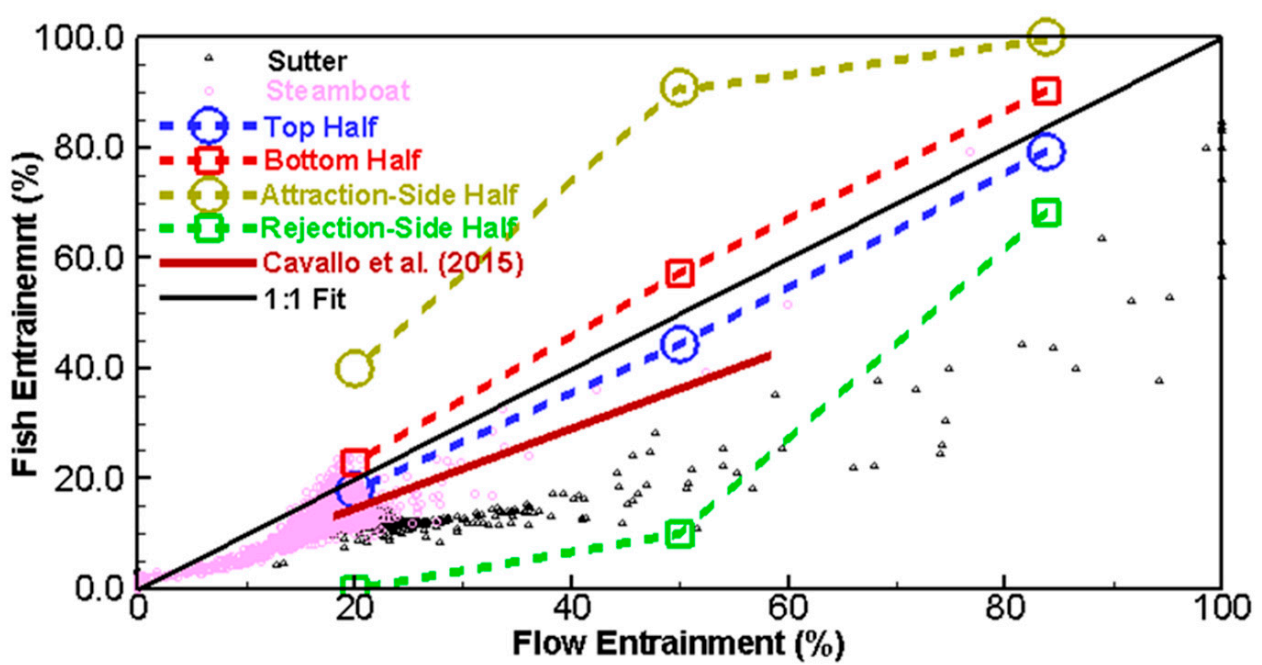

Figure 8. Computed fish entrainment rate versus flow diversion rate for the 90-degree juncture studied by Ramamurthy et al. [3]. Field data at the Sutter and Steamboat junctures of the Sacramento [32] and the linear regression developed by [31] based on the fish telemetry data at seven flow junctions of the Sacramento River are also plotted.

The results demonstrate that the upstream fish distribution has a profound impact on the fish entrainment efficiency. Fish near the bottom have a higher probability to be entrained into the side channel than the surface-oriented fish. For example, at $20 \%$ flow 
diversion, the fish entrainment efficiency differs by $25 \%$ between the top and bottom distributions, with the difference decreasing with increasing flow diversion rate. Most important, it is found that the difference in fish entrainment efficiency is the largest for different lateral distributions of fish (across the channel width). Almost all fish enter the side channel if fish are distributed over the entrainment half of the main channel crosssection. When fish are on the non-entrainment half, fish entrainment is possible only if the flow diversion is high (e.g., more than $30-40 \%$ ).

Figure 8 also includes the linear regression line based on the fish telemetry data measured at seven flow junctions on the Sacramento River (developed by [31]). Additionally, the fish tracking data measured by Romine et al. [32] at the Sutter and Steamboat junctures of the Sacramento River are also plotted. Discussion regarding this is offered later.

\subsection{Secondary Flow Effect on the Fish Entrainment}

The above results suggest that a strategy to attract or reject fish entrainment at a juncture is to redistribute fish towards desirable areas. At present, our knowledge of fish vertical distribution is limited, as most available data are 2D-based (or horizontal); in the future, 3D-based telemetry is recommended such as the use of tri-axial accelerometers. Lateral fish distribution has been measured using the fish telemetry/tag technology. For example, fish telemetry tracking was conducted by Steele et al. [19] along the Fremont Weir section of the Sacramento River; they showed that fish were distributed towards the outer bank of a river bend, due to the secondary flow generated. Therefore, the present numerical model is used next to explore the effect of a secondary flow on fish entrainment.

A new simulation is carried out in which a secondary flow is created by attaching a 180deg bend to the upstream of the juncture of the baseline case studied above (see Figure 9a). All flow conditions remain the same as the baseline with the straight main channel. The numerical model has a mesh of 562,800 cells. The incoming flow undergoes a 180-deg bend before reaching the juncture, and the fish distribution simulated corresponds to the top-half scenario. Three runs are carried out corresponding to three flow rates: 20\%, 50\%, and $83.8 \%$ flow diversion rates. To gain an understanding of the flow field, the predicted velocity on the free surface and the secondary flow and FDF on the cross-section upstream of the juncture are plotted in Figure $9 \mathrm{~b}$. The results show that a two-cell secondary flow is developed after waters exit the bend. The average secondary flow velocity is about $12 \%$ of the streamwise velocity. The FDF results indicate that $82 \%$ of the top-half of the passive fish are moving towards the outer bend (the entrainment side), so an increased fish entrainment is expected. This is confirmed by quantitatively comparing the fish entrainment rate with the results from the straight channel, shown in Figure 10. It is seen that the fish entrainment rate of the bend case with the top-half fish distribution is close to the result of the straight channel, entrainment-side fish distribution. The result clearly demonstrates that the secondary flow may alter the fish entrainment at a juncture significantly.

\subsection{Discussion of the Fish Entrainment Results}

The numerical model results of the present study may be used to interpret the field data. In the process, the model results are also partially supported by the measured fish entrainment data. For example, the computed relation of the fish entrainment rate versus flow diversion rate has been shown in Figure 8 for the straight channel juncture. In the figure, also plotted are the field data at the Sutter and Steamboat junctures of the Sacramento River by Romine et al. [32] and the linear regression curve developed by Cavallo et al. [31] based on the fish telemetry data at seven junctures of the Sacramento River. The dataset of [31] showed that fish entrainment rate varied between $10 \%$ and $40 \%$, while the flow diversion rate was between $18 \%$ and $60 \%$. These measured fish entrainment data points fall mostly within the region bounded by the top-half and non-entrainment-half curves of the numerical model. These field entrainment data may now be explained based on the present results. It has been reported that at the Georgiana Slough (GS) juncture of the Sacramento River [14], for example, migrating juveniles stayed mostly near the top 
$4 \mathrm{~m}$ of the water depth and fish were distributed towards the non-entrainment side. Both measured features would cause the fish entrainment efficiency to be less than 1.0, as shown in Figure 8. At the Sutter juncture, the measured fish entrainment rate was shown to be closer to the non-entrainment-side curve of the numerical model (see Figure 8). This may imply that the fish upstream of the juncture at the site were mostly distributed on the non-entrainment side. This is most likely due to the bend flow upstream of the juncture, as the results in the Section 3.4 demonstrate.

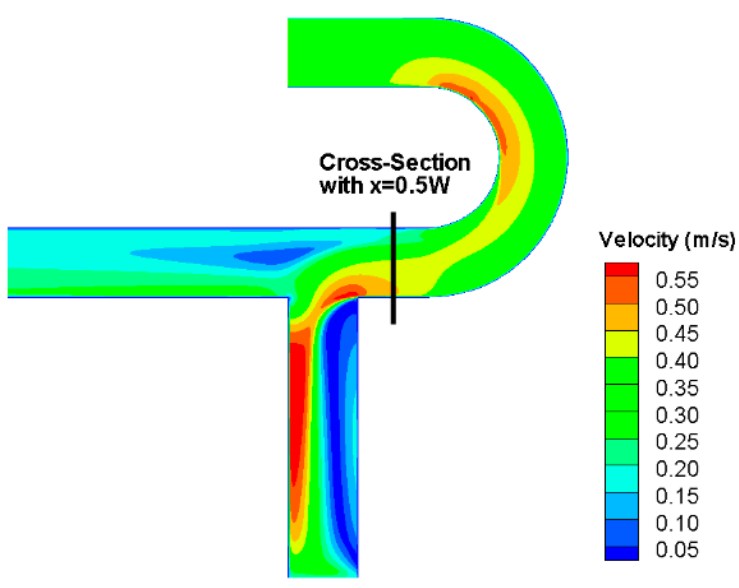

(a)
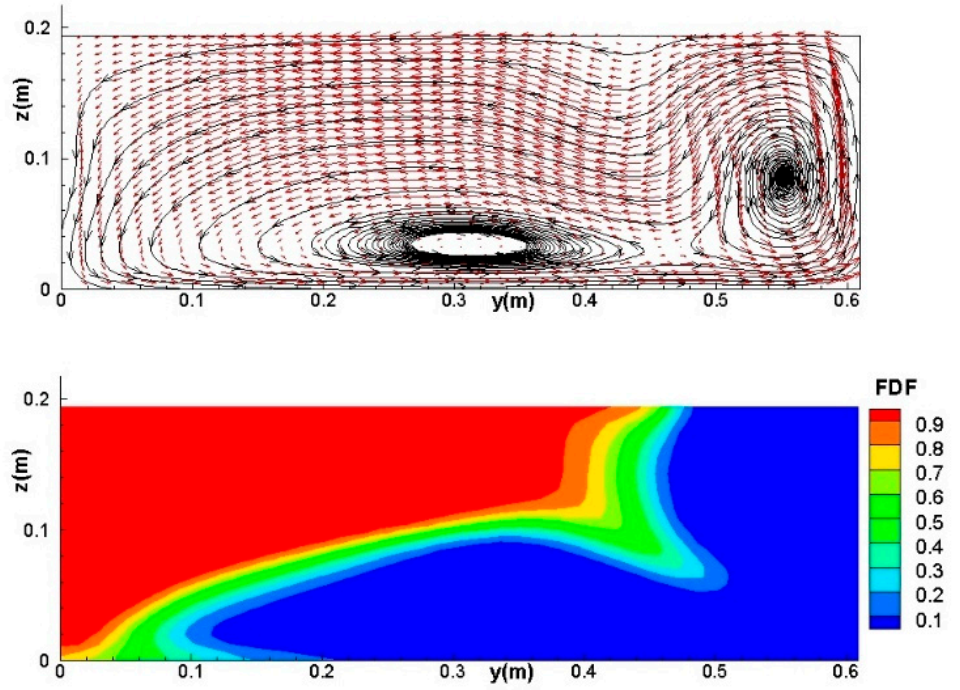

(b)

Figure 9. Planview of the (a) model domain and velocity field and (b) predicted secondary flow (top) and fish distribution function (bottom) at the main channel cross-section $0.5 \mathrm{~W}$ upstream of the juncture (looking downstream); the flow diversion rate is $50 \%$.

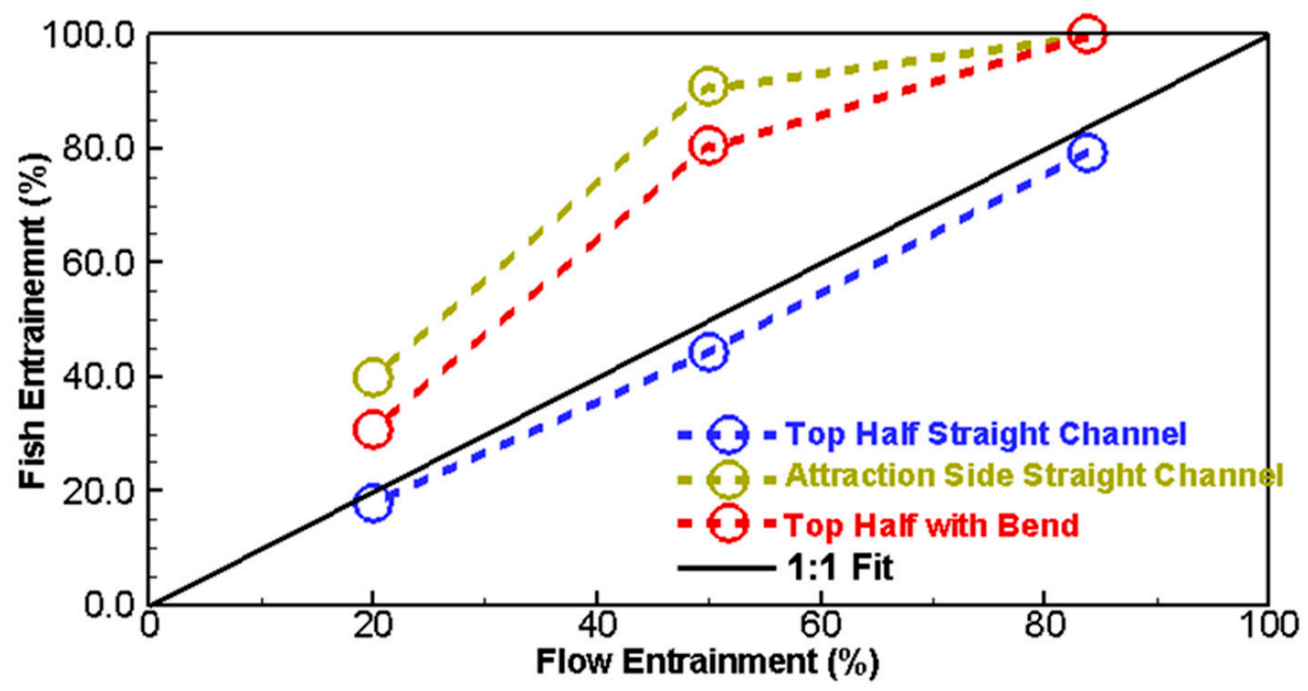

Figure 10. Fish entrainment rate versus the flow diversion rate with the effect of secondary flow set up by the 180-deg bend and the top-half fish distribution.

Another feature is that both the computed and the field data entrainment curves displayed two distinctive slopes when the entrainment rate increases (see the non-entrainmentside scenario curve). This suggests that the fish entrainment rate would be accelerated once the flow diversion rate is above a threshold (about 50\%). It is noticed that the slope of the measured data was less than the numerical model once the flow diversion rate 
was above $50 \%$, which may be explained as follows: The Sacramento River experiences daily reversed flows (i.e., the period during which the mean flow is from downstream to upstream) during the flood period under the influence of the tide [28]. Flow entrainment above $50 \%$ occurs primarily during the reverse period at the site. Significant flow eddies are present when flow reverses and the average flow velocity is smaller than that at the normal flow [28]. Both may cause fish to respond to local flow velocity gradient in addition to the flow velocity, which may have led to the decreased fish entrainment at the juncture. The passive assumption may not be valid under the reversed flow condition.

The finding that the upstream fish distribution has a profound impact on the fish entrainment efficiency is not new and has been discussed by other researchers. For example, Perry et al. [14] commented that both flow diversion rate and fish spatial distribution would influence the probability of fish entering a side channel. Using the fish tracking data at the GS juncture, they showed that the probability of fish entrainment into GS was much higher for fish positioned on the entrainment side than those on the opposite side. They concluded that "fish location in the cross-section was the most important determinant of an individual's probability of entrainment into Georgiana Slough." The previous studies of the issue, however, were mostly qualitative; this study provides a mechanistic and quantitative way to evaluate the effect of the fish distribution on entrainment.

In lieu of the finding of the importance of the secondary flow on fish entrainment, it is expected that the local bathymetric features may be manipulated to increase or decrease fish entrainment. Desirable secondary flows may be achieved by, for instance, installing instream structures such as the submerged vanes, floating curtains or large wood structures [56]. In the study of Daniels and Rhoads [57], for example, the effect of submerged large woody structures on the secondary circulation in curved streams was demonstrated. Both the location of the maximum velocity and strength of the secondary flow were altered. Perry et al. [14] suggested that simple guiding structures, such as a floating boom, could be effective in shifting the cross-stream fish distribution. For example, a floating log boom was successfully used to guide migrating juvenile salmon toward a surface passage structure at the Lower Granite Dam on the Snake River [58].

To test this, a simple straight plate vane is placed in the main channel upstream of the juncture of the baseline case model; the case is simulated to demonstrate that secondary flows may be generated by such a submerged vane and fish entrainment may be altered at the juncture. The layout of the vane case is shown in Figure 11a. The plate vane has a length $0.5 \mathrm{~W}$, thickness $0.01 \mathrm{~W}$, and submergence $50 \%$. The vane center is $1.612 \mathrm{~W}$ upstream of the juncture, and the vane is oriented $40^{\circ}$ from the flow direction based on the study of [56] that the $40^{\circ}$ angle is optimum.

The simulation is carried out corresponding to the $20 \mathrm{~T}, 50 \mathrm{~T}$ and $84 \mathrm{~T}$ scenarios of the baseline case-i.e., the flow diversion rate is $20 \%, 50 \%$ and $83.8 \%$, respectively. Fish is distributed with the top-half scenario at the channel inlet. The simulated flow velocity and FDF with the $50 \%$ diversion rate are plotted in Figure $11 \mathrm{~b}$, the predicted secondary flow created by the vane is shown in Figure 12, and the simulated fish entrainment rate is compared in Figure 13.

As expected, a secondary flow was developed by the submerged vane, and the fish entrainment rate was increased significantly. The rate curve moved up between the top-half and entrainment-half curves of the no-vane baseline cases. Increased fish entrainment was a direct result of the secondary flow induced by the submerged vane. 


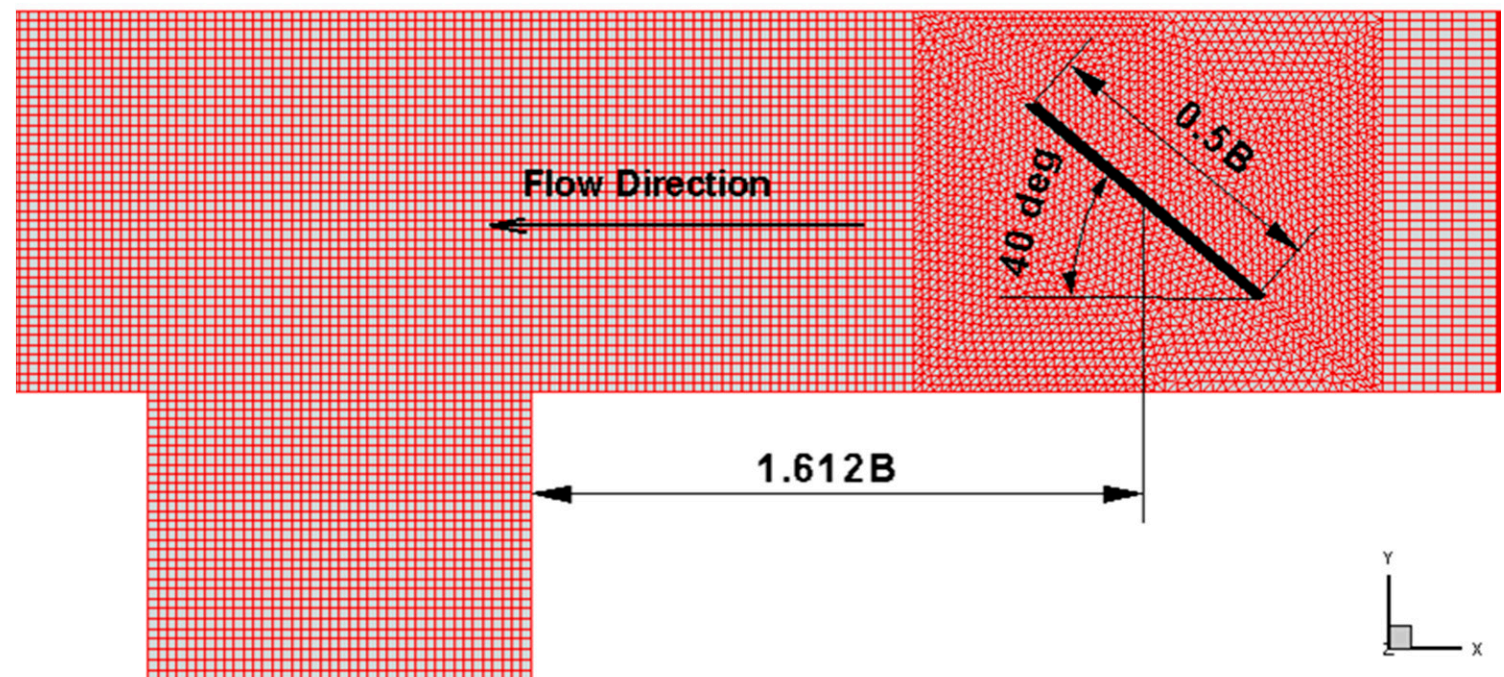

(a)

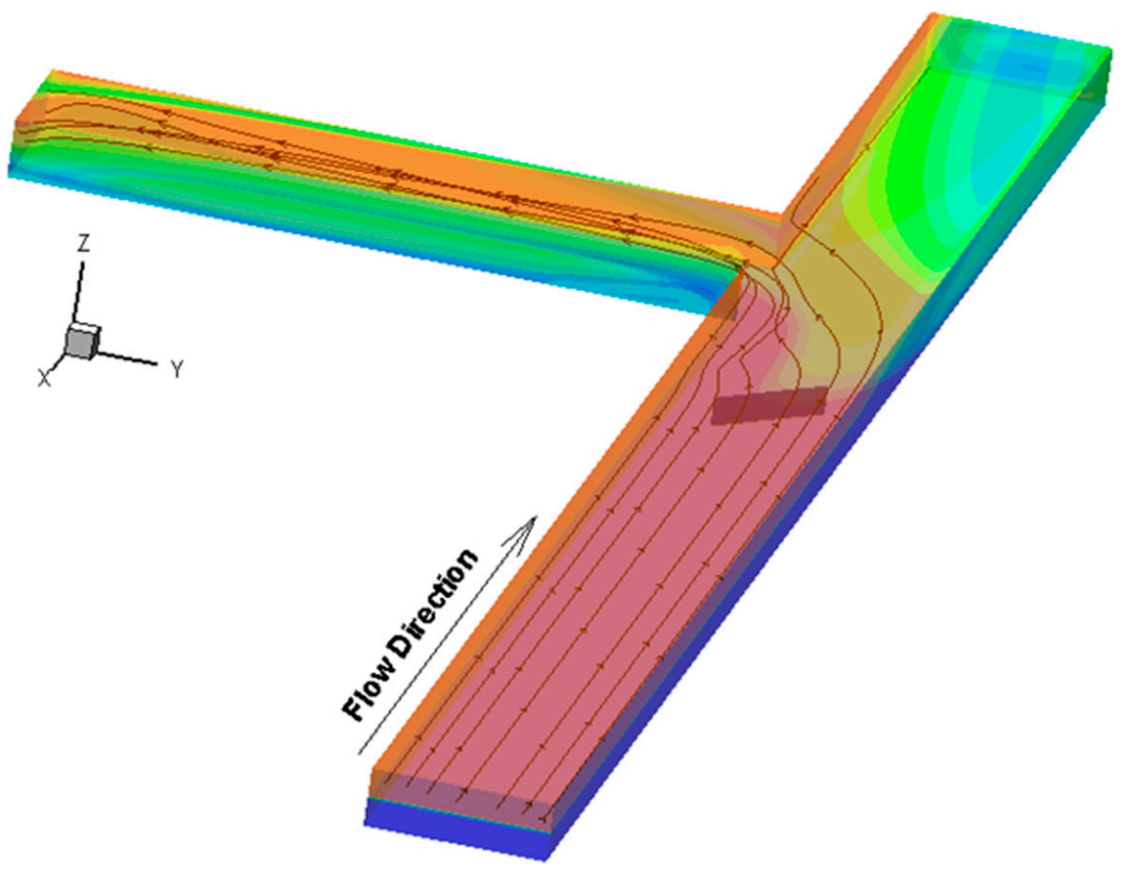

(b)

Figure 11. Schematic of the straight vane placed in the middle of the main channel upstream of the juncture with $40^{\circ}$ angle from the flow direction; (a) the model domain and mesh showing location, orientation, and dimensions of the vane; (b) the predicted fish distribution function field and flow streamlines on the mid-horizontal plane. 

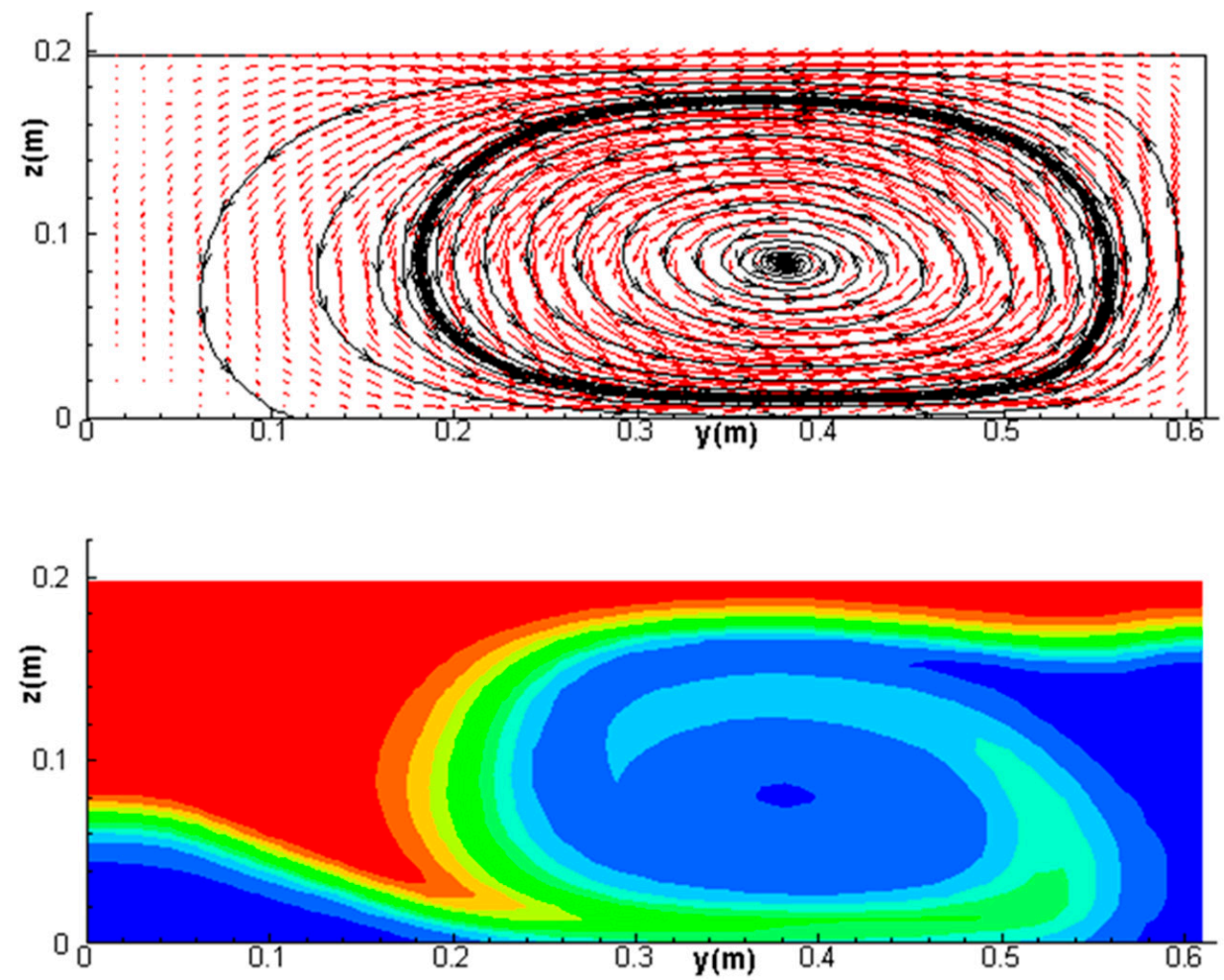

Figure 12. Predicted secondary flow (top) and Fish Distribution Function field (bottom) at the main channel cross-section $0.5 \mathrm{~W}$ upstream of the juncture for the vane case.

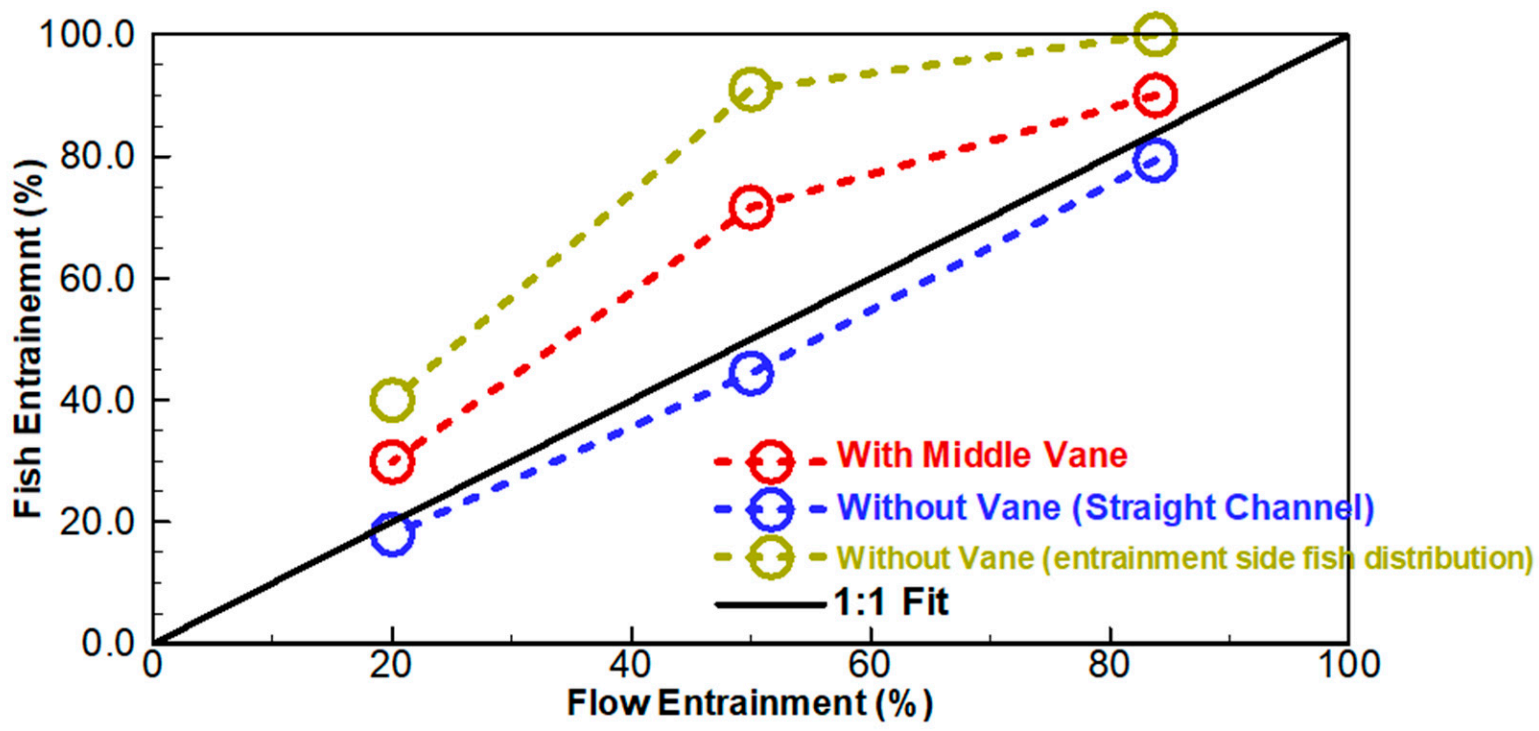

Figure 13. Computed fish entrainment rate for the vane case with the top-half fish distribution at the inlet (the top-half and entrainment-half results for the no-vane baseline cases are also shown).

\section{Conclusions}

Fish entrainment at a river juncture has been studied over the years. However, our understanding is still limited due to the complex nature of flow characteristics at such junctures. Past studies focused primarily on field measurements (both flow field and fish movement tracking) and development of empirical relations. More recently, research has moved towards a science-based approach which is predictive for future conditions and defensible for evaluation of project alternative and adaptive management. This study represents such an effort. Specifically, I propose that a numerical model approach has 
potential to be implemented to examine alternative effectiveness for fish entrainment and to adapt the design to improve these.

In this study, it is demonstrated that complex juncture flow features may be predicted well by the current 3D RANS-based models, and the passive-particle based Eulerian fish track model may yield insights into the fish entrainment characteristics at river junctures. For example, the numerical model results show that the cross-sectional fish distribution upstream of a juncture has a large impact on fish entrainment, with fish distribution towards the entrainment side promoting the most significant fish attraction, consistent with previous findings from field data. The numerical approach is not limited to existing condition scenarios and has the benefit of predicting the entrainment efficiency directly, for absolute or relative comparisons. The model results may be used to explain observed fish entrainment data and may also be used to evaluate management strategies to achieve fish attraction or rejection. For example, the present model is used to show that the secondary flow created in a river bend may have a great impact on fish entrainment at flow junctures, in agreement with the field observations. Using the model, it is also shown that a submerged vane may be used as a potential management option for increased fish attraction or rejection, as a properly placed submerged vane generates secondary flows upstream of a juncture.

It is acknowledged that the present model has a limitation that the passive-particle approach is used for fish tracking; such a model may be useful primarily at junctures of large rivers with water velocities in the main and side channels in excess of the fish swim capability. In addition to flow current, it is known that fish may also respond to other flow variables (e.g., acceleration, turbulence, and vorticity) and environmental parameters (e.g., temperature, turbidity, and light). Future research should focus on improving the passive-particle assumption so that the numerical fish will also respond to other variables; this means suitable fish perception-and-response rules need to be derived using field observation and data. It is planned that the Eulerian-Lagrangian Agent-based Model (ELAM) of Goodwin et al. [21] and Smith et al. [22] will be adopted in the future. ELAM is a fish perception-and-response model that has been successfully used for a fish attraction study at hydropower dams [22,24]. For improved success and reliability of the numerical fish model, more field studies are needed, focusing specifically on developing the fish perception-and-response rules relevant to river junctures.

Funding: This research was funded by the Science and Technology Office and the Bay Delta Office, U.S. Bureau of Reclamation, Denver, CO, USA.

Data Availability Statement: Data sharing not applicable.

Acknowledgments: Technical discussions with D.L. Smith, Engineer Research and Development Center, US Army Corps of Engineers, Vicksburg, MS, USA, are greatly appreciated; the research has been motivated, conceptualized, and supported by J. Israel, Bay Delta Office, U.S. Bureau of Reclamation, Sacramento, CA, USA; and peer review by B. Abban, U.S. Bureau of Reclamation, Denver, CO, USA, is acknowledged.

Conflicts of Interest: The author declares no conflict of interest.

\section{References}

1. Neary, V.S.; Odgaard, A.J. Three-dimensional flow structure at open channel diversions. J. Hydraul. Eng. 1993, 119, 1223-1230. [CrossRef]

2. Barkdoll, B.D.; Hagen, B.L.; Odgaard, A.J. Experimental comparison of dividing open-channel with duct flow in T-Junction. J. Hydraul. Eng. 1998, 124, 92-95. [CrossRef]

3. Ramamurthy, A.S.; Qu, J.; Vo, D. Numerical and experimental study of dividing open-channel flows. J. Hydraul. Eng. 2007, 133, 1135-1144. [CrossRef]

4. Babagoli Sefidkoohia, R.; Shahidib, A.; Ramezani, Y.; Kahed, M. Simulation of flow pattern in intake by using a numerical model. Water Harvest. Res. 2017, 2, 24-36. [CrossRef]

5. Bulle, H. Untersuchungen Über die Geschiebeableitung bei der Spaltung von Wasserläufen: Modellversuche aus dem Flussbaulaboratorium der Technischen Hochschule zu Karlsruhe; VDI: Karlsruhe, Germany, 1926. (In German) 
6. Dutta, S.; Garcia, M.H. Nonlinear Distribution of Sediment at River Diversions: Brief History of the Bulle Effect and Its Implications. J. Hydraul. Eng. 2018, 144, 03118001. [CrossRef]

7. Sommer, T.; Nobriga, M.L.; Harrell, W.C.; Batham, W.; Kimmerer, W.J. Floodplain rearing of juvenile Chinook salmon: Evidence of enhanced growth and survival. Can. J. Fish. Aquat. Sci. 2001, 58, 325-333. [CrossRef]

8. Jeffres, C.A.; Opperman, J.J.; Moyle, P.B. Ephemeral floodplain habitats provide best growth conditions for juvenile Chinook salmon in a California river. Environ. Biol. Fishes 2008, 83, 449-458. [CrossRef]

9. Bellmore, J.R.; Baxter, C.V.; Martens, K.; Connolly, P.J. The floodplain food web mosaic: A study of its importance to salmon and steelhead with implications for their recovery. Ecol. Appl. 2013, 23, 189-207. [CrossRef]

10. Roberts, J.J.; Rahel, F.J. Irrigation canals as sink habitat for trout and other fishes in a Wyoming drainage. Trans. Am. Fish. Soc. 2008, 137, 951-961. [CrossRef]

11. Buchanan, R.A.; Skalski, J.R.; Brandes, P.L.; Fuller, A. Route use and survival of juvenile Chinook salmon through the San Joaquin River Delta. N. Am. J. Fish. Manag. 2013, 33, 216-229. [CrossRef]

12. Nichols, F.H.; Cloern, J.E.; Luoma, S.N.; Peterson, D.H. The modification of an estuary. Science 1986, 231, 567-573. [CrossRef] [PubMed]

13. Perry, R.W.; Skalski, J.R.; Brandes, P.L.; Sandstrom, P.T.; Klimley, A.P.; Ammann, A.; MacFarlane, B. Estimating survival and migration route probabilities of juvenile Chinook salmon in the Sacramento-San Joaquin river delta. N. Am. J. Fish. Manag. 2010, 30, 142-156. [CrossRef]

14. Perry, R.W.; Romine, J.G.; Adams, N.S.; Blake, A.R.; Burau, J.R.; Johnston, S.V.; Liedtke, T.L. Using a non-physical behavioural barrier to alter migration routing of juvenile Chinook Salmon in the Sacramento-San Joaquin River Delta. River Res. Appl. 2014, 30, 192-203. [CrossRef]

15. Newman, K.B.; Brandes, P.L. Hierarchical modeling of juvenile Chinook salmon survival as a function of Sacramento-San Joaquin Delta water exports. N. Am. J. Fish. Manag. 2010, 30, 157-169. [CrossRef]

16. Brandes, P.L.; McLain, J.S. Juvenile Chinook Salmon Abundance, Distribution, and Survival in the Sacramento-San Joaquin Estuary; Brown, R.L., Ed.; Contributions to the Biology of Central Valley Salmonids; Fish Bulletin: Sacramento, CA, USA, 2001; Volume 179, pp. 39-99.

17. Post, J.R.; van Poorten, B.T.; Rhodes, T.; Askey, P.; Paul, A. Fish entrainment into irrigation canals: An analytical approach and application to the Bow River, Alberta, Canada. N. Am. J. Fish. Manag. 2006, 26, 875-887. [CrossRef]

18. Carlson, A.J.; Rahel, F.J. A basin wide perspective on entrainment of fish in irrigation canals. Trans. Am. Fish. Soc. 2007, 136, 1335-1343. [CrossRef]

19. Steel, A.; Lemasson, B.; Smith, D.L.; Israel, J. Two-Dimensional Movement Patterns of Juvenile Winter-Run and Late-Fall-Run Chinook Salmon at the Fremont Weir, Sacramento River, CA. In Project Report, ERDC/EL TR-17-10; ERDC-EL Vicksburg United States: Sacramento, CA, USA, 2017.

20. Goodwin, R.A. Hydrodynamics and Juvenile Salmon Movement Behavior at Lower Granite Dam: Decoding the Relationship Using 3-D Space-Time (CEL Agent IBM) Simulation. Ph.D. Thesis, Cornell University, Ithaca, NY, USA, 2004.

21. Goodwin, R.A.; Nestler, J.M.; Anderson, J.J.; Weber, L.J.; Loucks, D.P. Forecasting 3-D fish movement behavior using a EulerianLagrangian-agent method (ELAM). Ecol. Modell. 2006, 192, 197-223. [CrossRef]

22. Smith, D.L.; Nestler, J.M.; Johnson, G.E.; Goodwin, R.A. Species-specific spatial and temporal distribution patterns of emigrating juvenile salmonids in the Pacific Northwest. Rev. Fish. Sci. 2010, 18, 40-64. [CrossRef]

23. McNamara, J.M.; Fawcett, T.W.; Houston, A.I. An adaptive response to uncertainty generates positive and negative contrast effects. Science 2013, 340, 1084-1086. [CrossRef]

24. Goodwin, R.A.; Politano, M.; Garvin, J.W.; Nestler, J.M.; Hay, D.; Anderson, J.J.; Weber, L.J.; Dimperio, E.; Smith, D.L.; Timko, M.A. Fish navigation of large dams emerges from their modulation of flow field experience. Proc. Natl. Acad. Sci. USA 2014, 111, 5277-5282. [CrossRef]

25. Dabiri, J.O. Biomechanics: How fish feel the flow. Nature 2017, 547, 406-407. [CrossRef] [PubMed]

26. Oteiza, P.; Odstrcil, I.; Lauder, G.V.; Portugues, R.; Engert, F. A novel mechanism for mechanosensory-based rheotaxis in larval zebrafish. Nature 2017, 547, 445-448. [CrossRef] [PubMed]

27. Bever, A.J.; MacWilliams, M.L. Factors Influencing the Calculation of Periodic Secondary Circulation in a Tidal River: Numerical Modelling of the Lower Sacramento River, USA. Hydrol. Processes 2015, 30, 995-1016. [CrossRef]

28. Ramon, C.L.; Acosta, M.; Rueda, F.J. Hydrodynamic Drivers of Juvenile-Salmon Out-Migration in the Sacramento River: Secondary Circulation. J. Hydraul. Eng. 2018, 144, 04018042. [CrossRef]

29. Goodwin, R.A.; Lai, Y.G.; Smith, D.L.; Reeves, R.; McQuirk, J. Juvenile salmon movement/passage through the tidal free-flowing Georgiana Slough and Sacramento River junction emerge from swim orientation based on their recent past experience in water speed, the velocity gradient, water acceleration, and pressure. In Project Final Report; Department of Water Resources: Sacramento, CA, USA, 2018

30. Perry, R.W.; Brandes, P.L.; Burau, J.R.; Sandstrom, P.T.; Skalski, J.R. Effect of Tides, River Flow, and Gate Operations on Entrainment of Juvenile Salmon into the Interior Sacramento-San Joaquin River Delta. Trans. Am. Fish. Soc. 2015, 144, 445-455. [CrossRef]

31. Cavallo, B.; Gaskill, P.; Melgo, J.; Zeug, S.C. Predicting juvenile Chinook salmon routing in riverine and tidal channels of a freshwater estuary. Environ. Biol. Fishes 2015, 98, 1571-1582. [CrossRef] 
32. Romine, J.G.; Perry, R.W.; Stumpner, P.R.; Blake, A.R.; Burau, J.R. Effects of tidally varying river flow on entrainment of juvenile salmon into Sutter and Steamboat Sloughs. San Fr. Estuary Watershed Sci. 2021, 19, 1-17. [CrossRef]

33. Hance, D.J.; Perry, R.W.; Burau, J.R.; Blake, A.; Stumpner, P.; Wang, X.; Pope, A. Combining models of the critical dtreakline and the cross-sectional distribution of juvenile salmon to predict fish routing at river junctions. San Fr. Estuary Watershed Sci. 2020, 18,3 .

34. Lai, Y.G.; Weber, L.J.; Patel, V.C. Non-hydrostatic three-dimensional method for hydraulic flow simulation-Part I: Formulation and verification. J. Hydraul. Eng. 2003, 129, 196-205. [CrossRef]

35. Lai, Y.G.; Smith, D.L.; Bandrowski, D.J.; Xu, Y.; Woodley, C.M.; Schnell, K. Development of a CFD model and procedure for flows through in-stream structures. J. Appl. Water Eng. Res. 2021. [CrossRef]

36. Pope, S.B. Turbulent Flows; Cambridge University Press: Cambridge, UK, 2000.

37. Launder, B.E.; Spalding, D.B. The numerical computation of turbulent flows. Comput. Methods Appl. Mech. Eng. 1974, 3, 269-289. [CrossRef]

38. Gross, E.S.; Holleman, R.C.; Thomas, M.J.; Fangue, N.A.; Rypel, A.L. Development and Evaluation of a Chinook Salmon Smolt Swimming Behavior Model. Water 2021, 13, 2904. [CrossRef]

39. Blake, A.; Horn, M.J. Acoustic tracking of juvenile Chinook salmon movement in the vicinity of the delta cross channel, Sacramento river, California-2001 study results. In USGS Open-File Reports; USGS: Washington, DC, USA, 2004.

40. Zeng, Y. Hydrodynamics and Performance Evaluations of Fish Passages Based on Computational Fluid Dynamics and IndividualBased Methods. Ph.D. Thesis, Deptartment Civil Engineering, The Pennsylvania State University, University Park, PA, USA, 2021.

41. Nelson, W.R.; Freidenburg, L.K.; Rondorf, D.W. Swimming performance of subyearling Chinook salmon. In Identification of the Spawning, Rearing, and Migratory Requirements of fall Chinook Salmon in the Columbia River Basin; Rondorf, D.W., Miller, V.H., Eds.; Bonneville Power Administration: Portland, OR, USA, 1994; pp. 39-62.

42. Taylor, E.H. Flow characteristics at rectangular open-channel junctions. Trans. ASCE 1944, 107, 893-912. [CrossRef]

43. Grace, J.L.; Priest, M.S. Division of Flow in Open Channel Junctions. Bulletin No. 31; Engineering Experimental Station, Polytechnic Institute: Auburn, AL, USA, 1958.

44. Tanaka, K. The improvement of the inlet of the Power Canal. In Proceedings of the Transactions of the Seventh General Meeting of IAHR, Lisboa, Portugal, June 1957; Volume 1, p. 17.

45. Law, S.W.; Reynolds, A.J. Dividing flow in an open channel. J. Hydraul. Div. 1966, 92, 4730-4736. [CrossRef]

46. Hager, W.H. An approximate treatment of flow in branches and bends. J. Mech. Eng. Sci. 1984, 198, 63-69. [CrossRef]

47. Gohari, S. Laboratory investigation of separation line at the intake sand its relation to sediment control. In Proceedings of the 9th International Congress on Civil Engineering, Isfahan University of Technology, Isfahan, Iran, 8 May 2012.

48. Liepsch, D.; Moravec, S.; Rastogi, A.K.; Vlachos, N.S. Measurement and calculations of laminar flow in a ninety degree bifurcation. J. Biomech. 1982, 15, 473-485. [CrossRef]

49. Shettar, A.; Murthy, K. A numerical study of division of flow in open channels. J. Hydraul. Res. 1996, 34, 651-675. [CrossRef]

50. Vasquez, J.A. Two-dimensional numerical simulation of flow diversions. In Proceedings of the 17th Canadian Hydrotechnical Conference, Edmonton, Alberta, 17-19 August 2005.

51. Neary, V.S.; Sotiropoulos, F. Numerical investigation of laminar flows through 90-degree diversion of rectangular cross-section. Comput. Fluids 1996, 25, 95-118. [CrossRef]

52. Issa, R.I.; Oliveira, P.J. Numerical prediction of phase separation in two-phase flow through T-junction. Comput. Fluids 1994, 23, 347-372. [CrossRef]

53. Neary, V.S.; Sotiropoulos, F.; Odgaard, A.J. Three-dimensional numerical model of lateral-intake inflows. J. Hydraul. Eng. 1999, 125, 126-140. [CrossRef]

54. Heer, A.d.; Mosselman, E. Flow structure and bedload distribution at alluvial diversions. River Flow 2004. In Proceedings of the Second International Conference on Fluvial Hydraulics, Napoli, Italy, 23-25 June 2004; Volume 1, pp. 801-806.

55. Qu, J. Three-Dimensional Turbulence Modeling for Free Surface Flows. Ph.D. Thesis, Concordia University, Montreal, QC, Canada, 2005.

56. Marelius, F.; Sinha, S.K. Experimental Investigation of Flow Past Submerged Vanes. J. Hydraul. Eng. 1998, 124, 542-545. [CrossRef]

57. Daniels, M.D.; Rhoads, B.L. Influence of a large woody debris obstruction on three-dimensional flow structure in a meander bend. Geomorphology 2003, 51, 159-173. [CrossRef]

58. Cash, K.M.; Adams, N.S.; Hatton, T.W.; Jones, E.C.; Rondorf, D.W. Three Dimensional Fish Tracking to Evaluate the Operation of the Lower Granite Surface Bypass Collector and Behavioral Guidance Structure during 2000; US Geological Survey Report to US Army Corps of Engineers: Walla Walla, DC, USA, 2002; Volume 73. 